\title{
Publisher Correction: From drop impact physics to spray cooling models: a critical review
}

\author{
Jan Breitenbach ${ }^{1}$ (D) - Ilia V. Roisman ${ }^{1} \cdot$ Cameron Tropea $^{1}$
}

Published online: 26 April 2018

C) Springer-Verlag GmbH Germany, part of Springer Nature 2018

\section{Publisher Correction:}

Experiments in Fluids (2018) 59:55

https://doi.org/10.1007/s00348-018-2514-3

The article category has been published incorrectly due to processing error. The correct category should read "Review Article".

We apologize for this lapse.

The Publisher

Ilia V. Roisman

roisman@sla.tu-darmstadt.de

1 Institute for Fluid Mechanics and Aerodynamics, Technische

Universität Darmstadt, Darmstadt, Germany 